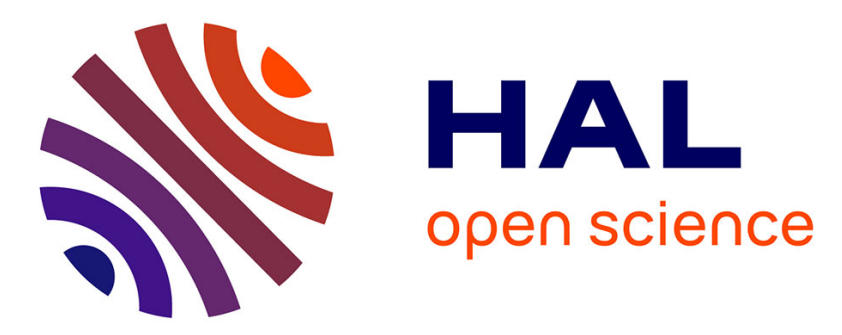

\title{
Transformer operating conditions under introduction of PV and EVs in an eco-district
}

\author{
Xuan-Linh Dang, Marc Petit, Paul Codani
}

\section{To cite this version:}

Xuan-Linh Dang, Marc Petit, Paul Codani. Transformer operating conditions under introduction of PV and EVs in an eco-district. IEEE Power and Energy Society General Meeting, Jul 2015, Denver, France. 10.1109/PESGM.2015.7286380 . hal-01266885

\section{HAL Id: hal-01266885 \\ https://hal-centralesupelec.archives-ouvertes.fr/hal-01266885}

Submitted on 7 Feb 2016

HAL is a multi-disciplinary open access archive for the deposit and dissemination of scientific research documents, whether they are published or not. The documents may come from teaching and research institutions in France or abroad, or from public or private research centers.
L'archive ouverte pluridisciplinaire HAL, est destinée au dépôt et à la diffusion de documents scientifiques de niveau recherche, publiés ou non, émanant des établissements d'enseignement et de recherche français ou étrangers, des laboratoires publics ou privés. 


\section{Transformer Operating conditions under introduction of PV and EVs in an Eco-district}

\author{
Xuan-Linh Dang \\ Marc Petit \\ Department of Power and Energy Systems \\ E3S SUPELEC Systems Sciences \\ 91190 Gif-sur-Yvette, FRANCE \\ xuan-linh.dang@supelec.fr
}

\author{
Paul Codani \\ Advanced Technologies and Innovation Research Department \\ PSA Peugeot Citroen \\ 78140 Velizy-Villacoublay, France \\ paul.codani@mpsa.com
}

\begin{abstract}
An analysis of the operating conditions of a power transformer with the introduction of photovoltaic (PV) panels and Electric Vehicles (EV) in an eco-district is conducted. The study focuses on: (a) determining the optimal transformer sizing when there is neither PV nor EV; and (b) characterizing the overloading periods of the transformer induced by the penetration of PV sources and EVs in the district. We compare two EV integration strategies: they are either considered as unmanaged loads, or controlled by an Energy Management System (EMS) with Vehicle-to-Grid (V2G) capabilities. Transformer operating curves and rated power are deduced from technical standards supplied by Schneider Electric. The results show that EVs and PV introduction has a substantial impact on overloading periods. However, the latters are seriously mitigated both in terms of energy flows and peak power with the implementation of the EMS.
\end{abstract}

Index Terms-Energy Management System; Micro-grid; Power Transformer; Smart Charging; Vehicle-To-Grid

\section{INTRODUCTION}

In order to cope with the objectives of reduction in both air pollution and $\mathrm{CO}_{2}$ emissions, the penetration of Renewable Energy Sources (RES) (such as photovoltaic (PV) panels, wind turbines, etc.) in power systems has substantially increased during the last few years. Similarly, plug-in Electric Vehicles (EV) moved by electric motors and powered by electrochemical batteries represent a promising solution with respect to these goals. With the upcoming decrease in battery costs, and the deployment of charging stations, EV sales are expected to increase within the next few years.

However, the increasing penetration of these two new units brings up concerns regarding their impacts on the electrical grid security. On one hand, RES are asynchronous and intermittent by nature, and distributed at the distribution level. They could trigger local congestion, frequency- and voltagerelated problems, as well as system wide balancing issues [1][3]. On the other hand, if not managed properly, the massive

This research is a part of the Energy Positive IT 2.0 project and benefit from the support of the Conseil General de lEssonne.

Paul CODANI is preparing a $\mathrm{PhD}$ with the Armand Peugeot Chair dedicated to hybrid technologies and economy of electro mobility, and is funded by PSA Peugeot Citroen.

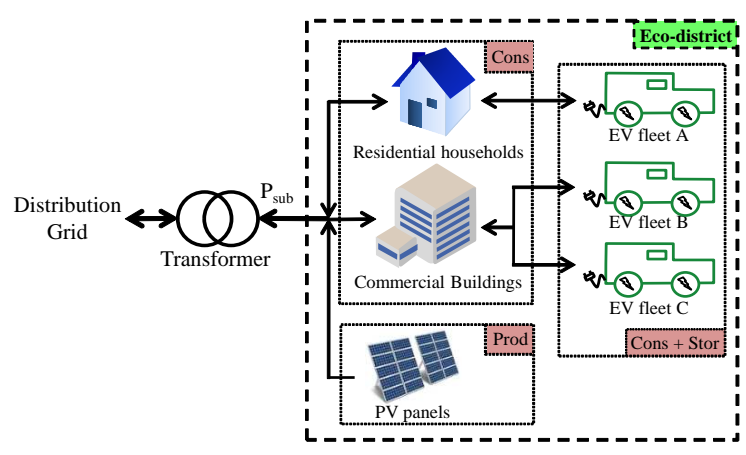

Fig. 1. System Overview

introduction of plug-in vehicles could jeopardize grid security [4]-[6].

In this paper, we are concerned with the overloading periods of the transformer of an eco-district induced by the introduction of PV panels and EVs. Initially, such a district, pictured in Fig. 1, only has residential and commercial facilities. It is connected to the distribution grid through an oil-immersed power transformer.

First, we propose an approach to determine the optimal rated power (in $\mathrm{kVA}$ ) of the transformer when there is neither PV nor EV penetration. Then, we assess the impacts of the introduction of PV units and EVs on the operating conditions of the transformer. At this point, EVs are considered as dumb loads, i.e. they abide by a charge-as-plugged strategy. Finally, we conduct the same analysis considering that EVs have bidirectional capabilities, i.e. they can inject power back to the grid, and that their charging patterns are controlled by an Energy Management System (EMS), whose aim is to mitigate the transformer overloading periods.

As underlined in [7], very little research has been conducted on the coupling of microgrid energy management with Vehicle-to-grid (V2G) strategies. The main contributions of this paper are:

- an approach for an optimal sizing of the rated power of a distribution transformer, based on its load profile over a whole year and on technical guidelines from a transformer manufacturer; 
- a method to analyze the operating mode of the power transformer during the overloading periods;

- an optimal Energy Management System for the microgrid of the eco-district connected to the distribution grid. It includes residential and commercial consumption units; and three-different types of EV fleets;

- a V2G system taking into account different types of EV fleets with their users behaviors and a smart charging strategy for each EV fleet.

The paper is organized as follows. Section II provides a description of the system understudy and all its components. In section III, the transformer is characterized including the optimal sizing and the definitions of the overloading assessment criteria and the EMS is described. Section IV features the simulation use cases and the associated results. Finally, section $\mathrm{V}$ is the conclusion.

\section{ECO-DISTRICT ENERGY SYSTEMS DESCRIPTION}

\section{A. Residential consumption modeling}

The residential consumption model is based on the study of Ian and Murray [8], in which a stochastic model is proposed to simulate the habitants behaviors. More specifically, the duration of electricity use in households is highly dependent on the timing of the occupants activities. Thus, the use of electric appliances, lighting, heating and domestic hot water within a residential household are also taken into in the model.

\section{B. Commercial building modeling}

A load model is built to simulate the electric consumption of the commercial building, taking into account the difference between working days and weekend; and typical load shape.

From commercial building data, it is observed that most buildings have a base load during the night time. In the early morning, the buildings electric demand increases for cooling/warming depending on the outdoor air temperature. This will trigger a short-lived load spike called morning start-up. Later, as people come to work in the building, the electricity consumption increases with the arrival of occupants. Its value varies daily, seasonally and yearly. After working time, the power consumption reduces quite significantly, due to the fact that electric appliances are successively turned off.

\section{Electric Vehicle fleet modeling}

All EVs are assumed to be full-electric vehicles. They have a $22 \mathrm{kWh}$ battery with a state of charge (SOC) in the range [20\%, 90\%]. These values are based on the optimal operation range of the battery. The EV fleet is shared into three different sub-fleets:

- EV fleet A: people living in the eco-district. These EV are typically plugged-in during the night, and leave in the morning to go to work and come back at late afternoon;

- EV fleet B: people working in the eco-district. These EVs typically arrive in the morning in the eco-district, and leave in the late afternoon. They charge at work during the day;
- EV fleet C: a company fleet, for instance belonging to the mail services. These EVs are typically used from early morning to noon for the first-round deliveries, and from the early afternoon to the middle of the afternoon for the second-round deliveries.

Several driver behaviors are considered. First, the drivers of fleet B are divided into two categories: (a) the fleet of drivers having an ordinary behavior, that is charging at home during the night and participating in the EMS during the day; and (b) the fleet of drivers who aim at charging the most as they can at work, thus charging only the required energy for their morning trip during the night at home, and not participating in the EMS during the day.

Then, range anxiety is taken into account for all the drivers: when they inform their EV controller with their future driving needs (see section III-C2), we assume that they overestimate their future trip distances and that they always provide the EV controller with their yearly maximum distance traveled.

Based on [9], the Electric Vehicle Supply Equipment (EVSE) powers are distributed according to table I. Home charging is mainly done at low power, while working charging stations are more equally distributed (although fast charging is still marginal). Finally, the company fleet has $22 \mathrm{~kW}$ EVSEs only.

TABLE I

EVSE REPARTITIONS

\begin{tabular}{lccc}
\hline EVSE power plug & Fleet A & Fleet B & Fleet C \\
\hline Slow (a) - 3kW & $93 \%$ & $35 \%$ & $0 \%$ \\
Slow (b) - 7kW & $7 \%$ & $34 \%$ & $0 \%$ \\
Intermediate charging - 22kW & $0 \%$ & $29 \%$ & $100 \%$ \\
Fast charging - 43kW & $0 \%$ & $2 \%$ & $0 \%$ \\
\hline
\end{tabular}

The EV fleets model is dynamic and stochastic. EV fleets average distance trip (D), departure time $\left(\mathrm{T}_{d}\right)$, daily number trips $(\mathrm{N})$ and seasonal energy consumption (E) are obtained from PSA internal data and from the CROME project results and from French government agencies [10], [11] as described in table II. Then, trips distances and departure times are distributed according to Gaussian distributions with mean $(\mu)$ and standard deviations $(\sigma)$ values provided in table II.

TABLE II

EV FLEET TRIP CHARACTERISTICS

\begin{tabular}{|l|l|l|l|l|l|l|}
\hline \multirow{2}{*}{ Parameters } & \multicolumn{2}{|c|}{ Fleet A } & \multicolumn{2}{c|}{ Fleet B } & \multicolumn{2}{c|}{ Fleet C } \\
\cline { 2 - 7 } & $\mu$ & $\sigma$ & $\mu$ & $\sigma$ & $\mu$ & $\sigma$ \\
\hline \multirow{2}{*}{$\mathrm{D}(\mathrm{km})$} & 22 & 4.5 & 22 & 4.5 & $50^{a}$ & $10^{a}$ \\
\cline { 3 - 8 } & & & & & $30^{b}$ & $10^{b}$ \\
\hline \multirow{2}{*}{$\mathrm{T}_{d}(\mathrm{~h})$} & $8^{a}$ & $2^{a}$ & $8^{a}$ & $2^{a}$ & $7^{a}$ & $0.5^{a}$ \\
\cline { 2 - 7 } & $18^{b}$ & $2^{b}$ & $18^{b}$ & $2^{b}$ & $14^{b}$ & $0.5^{b}$ \\
\hline $\mathrm{N}$ & \multicolumn{2}{|c|}{2} & \multicolumn{2}{|c|}{2} \\
\hline $\mathrm{E}(\mathrm{kWh} / \mathrm{km})$ & \multicolumn{2}{|c|}{ Winter: $\mathrm{c}_{w}=0.18 / /$ Summer: $\mathrm{c}_{s}=0.13$} \\
\hline
\end{tabular}

${ }^{a}$ A.M. values, ${ }^{b}$ P.M. values 


\section{PV production data}

The photovoltaic generation data has been measured in the area of Paris over one full year.

\section{TRANSFORMER AND EMS CHARACTERIZATIONS}

In this section, all active and apparent powers are respectively provided in $\mathrm{kW}$ and $\mathrm{kVA}$.

\section{A. Optimal transformer sizing}

In this part, the approach used to size the transformer is presented. It is based on the technical guidelines provided by a transformer manufacturer [12]. To optimize the rated power (in $\mathrm{kVA}$ ) of the transformer, it is necessary to analyze its load profile at this step, induced only by the residential and commercial loads within a whole year. The net instantaneous power, $\mathrm{P}_{\text {sub }}(\mathrm{t})$, at the substation during the $\mathrm{j}^{\text {th }}$ day is calculated according to (1):

$$
P_{\text {sub }}^{j}(t)=P_{\text {resi }}^{j}(t)+P_{c o m}^{j}(t)
$$

where $\mathrm{P}_{\text {resi }}^{j}(\mathrm{t})$ and $\mathrm{P}_{\text {com }}^{j}(\mathrm{t})$ are respectively the consumption of residential households and commercial buildings.

Then, the yearly maximum substation power, $\mathrm{P}_{\text {sub_max }}$, is deduced from the daily maximum substation power as described by (2):

$$
P_{\text {sub_max }}=\max _{j}\left(\max _{t \in j}\left(P_{\text {sub }}^{j}(t)\right)\right) \text { with } 1 \leq j \leq 365
$$

From this value, the optimal rated power is determined according to the algorithm below:

1: Build the overloading limitation curve: $P_{s u b}^{\lim }(t)=f\left(t_{d}\right)$

2: $\alpha \leftarrow 0$ Initialization of $\alpha\}$

3: sized $\leftarrow$ false

while $\overline{\text { sized }}$ do

$P_{\text {size }} \leftarrow \alpha \times P_{\text {sub_max }}$

for all $i$ such that $0 \leq i \leq n$ do

7: $\quad P_{\text {sub_ave }}^{i} \leftarrow \sum\left(\int_{t_{j}}^{t_{k}}\left(\left|P_{\text {sub }}^{i}(t)\right|-P_{\text {size }}\right) \mathrm{d} t\right) / \sum\left(t_{k}-\right.$ $\left.t_{j}\right)$, with $\left|P_{s u b}^{i}(t)\right|>P_{\text {size }}$ during $\left[t_{k}, t_{j}\right]$

8: $\quad t_{d}^{i} \leftarrow \sum\left(t_{k}-t_{j}\right)$

9: $\quad$ end for

10: $\quad$ if $\exists i \in[1, n]\left(P_{\text {sub_ave }}^{i}+P_{\text {size }}\right) * 100 / P_{\text {size }}>P_{\text {sub }}^{l i m}\left(t_{d}^{i}\right)$ then

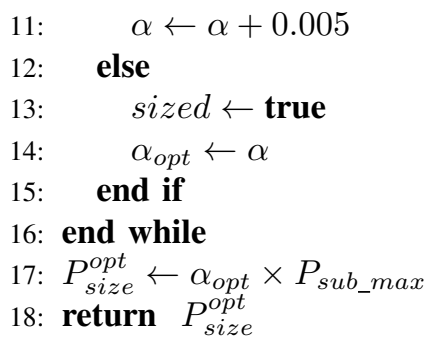

The optimal apparent power of the transformer is determined based on a power factor of 0.928 in order to avoid penalties when supplying energy to the consumers [12]:

$$
S_{\text {opt }}=\frac{P_{\text {size }}^{\text {opt }}}{0.928}
$$

To take into account the growth of the demand, a $25 \%$ security factor is added to get the rating power $\mathrm{S}_{\text {rated }}$. Then, we choose the commercial transformer with the closest power. Finally, the active rated power $\mathrm{P}_{\text {rated }}$ is calculated with a low power factor $(0.8)$ to be conservative.

$$
S_{\text {rated }}=1.25 \times S_{\text {opt }}
$$

\section{B. Transformer Operating Conditions Analysis}

In this scenario, we introduce PV panels on the roof of the commercial facilities, and EVs which charge according to a "charge-as-plugged" strategy. In other words, the EV fleet is not controlled by any external operator, and drivers plug-in as soon as possible (reflecting a normal and intuitive behavior).

Based on the hypothesis detailed in section II-C, the consumption of all EVs, $\mathrm{P}_{E V}(\mathrm{t})$, is calculated. Its value is computed on a minute-basis. It differs significantly from one day to the others and from one season to the other. Then, the instantaneous net power is described by (5):

$$
P_{\text {sub }}(t)=P_{P V}(t)-\left(P_{\text {resi }}(t)+P_{\text {com }}(t)+P_{E V}(t)\right)
$$

To characterize the overloading periods, the average daily substation power and the cumulative durations of the overloading periods are also calculated according to the equations provided in the algorithm. Moreover, the energy $\mathrm{E}_{e x}$ is determined by (6) when the substation power is overloaded:

$$
\begin{gathered}
E_{\text {ex }}=\sum_{i=1}^{n}\left(\int_{t_{j}}^{t_{k}}\left(\left|P_{\text {sub }}^{i}(t)\right|-P_{\text {rated }}\right) \mathrm{d} t\right), \\
\text { with }\left|P_{\text {sub }}^{i}(t)\right|>P_{\text {rated }}
\end{gathered}
$$

with $\left[\mathrm{t}_{j}, \mathrm{t}_{k}\right]$ the overloading time interval during $\mathrm{i}^{\text {th }}$ the day.

\section{Energy Management System}

1) District Energy Management System: At each time interval, the power flow, $\mathrm{P}_{\text {flow }}(\mathrm{t})$, between the micro-grid and the distribution grid (excluding the available EVs for the EMS) is calculated as following:

$P_{\text {flow }}(t)=P_{P V}(t)-\left(P_{\text {resi }}(t)+P_{\text {com }}(t)+P_{E V \_n o n E M S}(t)\right)$

where $\mathrm{P}_{E V \_n o n E M S}(\mathrm{t})$ denotes the consumption of EVs that are not available for the EMS most of the time, because they need to charge at full power for transportation needs. Then, based on the power flexibility that the EVs can provide (see (10)), the EMS calculates the power $\mathrm{P}_{E V_{-} E M S}(\mathrm{t})$ that has to be supplied by the available EV fleets. It depends on the current balance between supply and demand in the district as shown in Fig. 2. The mathematical formulation is described by (8):

$$
\begin{aligned}
& P_{\text {EV_EMS }}(t) \\
& =\left\{\begin{array}{l}
\max \left(P_{\text {charg }}(t),-P_{\text {flow }}(t)-P_{\text {rated }}\right), \text { cases A or B } \\
\max \left(P_{\text {charg }}(t),\left|P_{\text {flow }}(t)\right|-P_{\text {rated }}\right), \text { case C } \\
\max \left(P_{\text {disch }}(t),\left|P_{\text {flow }}(t)\right|-P_{\text {rated }}\right), \text { case D }
\end{array}\right.
\end{aligned}
$$




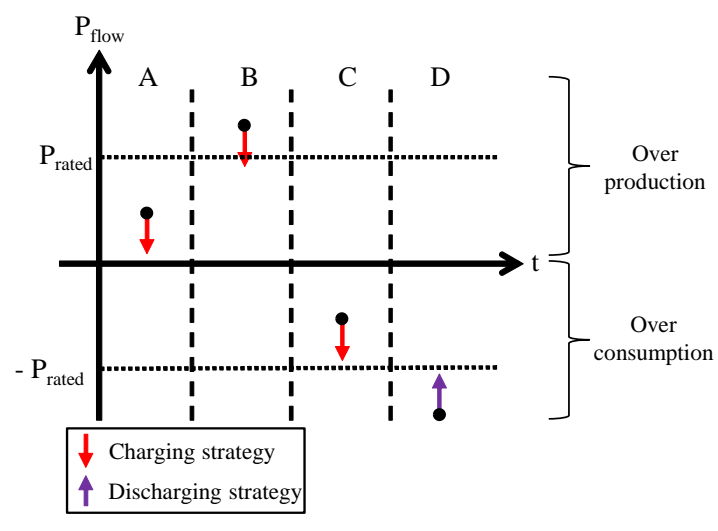

Fig. 2. Energy Management System strategy in the district

where $\mathrm{P}_{\text {charg }}(\mathrm{t})$ and $\mathrm{P}_{\text {disch }}(\mathrm{t})$ denote respectively the charging and discharging power flexibilities that can be provided by the EVs.

The objective of this EV power management is to maximize EVs charging power during the off-peak periods (cases A, B and $\mathrm{C}$ in Fig. 2) either from the PV (case A, B) or from the distribution grid (case $\mathrm{C}$ ); and to minimize the discharging energy from available EVs when the demand has reached the peak load or when the generation is too low to supply to the total demand (case D in Fig. 2). Finally, the net power flow at the substation level is given by (9):

$$
P_{\text {sub }}(t)=P_{\text {flow }}(t)+P_{E V_{-} E M S}(t)
$$

2) EV fleet smart charging regime: Once the required power from the available EVs $\mathrm{P}_{E V_{-} E M S}(\mathrm{t})$ has been determined by the EMS, it must be dispatched among those vehicles. If EV charging is ordered, we choose to first charge the EVs that have the biggest difference (in absolute value) between their current SOC and their required energy for next trip $\left(\operatorname{SOC}_{r e q}^{i}\left(\mathrm{t}_{d}\right)\right)$. On the contrary, we consecutively discharge the EVs that have the highest SOC.

To respect the future driving needs, each EV is able to decide for each moment whether to participate in the EMS or to charge quickly for transportation. Therefore, individual EVs provide the EMS with their available charging powers over the next timeframe as described by (10):

$$
\begin{aligned}
& P_{\text {charg }}^{i}(t)=-\min \left(P_{E V S E}^{i}, \frac{S O C_{\text {max }}^{i}-S O C^{i}(t)}{\Delta t}\right) \\
& P_{\text {disch }}^{i}(t)=\min \left(P_{E V S E}^{i}, \frac{S O C^{i}(t)-S O C_{r e q}^{i}(t+\Delta t)}{\Delta t}\right)
\end{aligned}
$$

Where $\mathrm{P}_{\text {charg }}^{i}(\mathrm{t})$ and $\mathrm{P}_{\text {disch }}^{i}(\mathrm{t})$ are respectively the available charging and discharging powers of $\mathrm{i}^{\text {th }} \mathrm{EV}$ for the next time interval, $\mathrm{P}_{E V S E}^{i}$ is the EVSE power; $\operatorname{SOC}^{i}(\mathrm{t}), \mathrm{SOC}_{\max }^{i}$ $\mathrm{SOC}_{r e q}^{i}(\mathrm{t})$ denote respectively the current, the maximum and the required state of charge for the $\mathrm{i}^{\text {th }} \mathrm{EV}$.

It is noticeable that we assume EVs to have a good estimation of their future trip distances and departure times.
This could be achieved in practice by either implementing a machine learning algorithm, the EV controller being able to estimate future driving needs depending on the previous ones, or by having the EV user directly informing the EV controller with its future driving needs (through, for instance, a smartphone application).

\section{RESULTS AND DisCUSSION}

\section{A. Simulation use cases}

We consider that 800 people are living in the eco-district, and that 1000 persons are working there. Then, it is assumed that $20 \%$ of the living people and $10 \%$ of the working people own an electric vehicle (fleets A and B). Additionally, the surface area of the PV panels is supposed to be $3000 \mathrm{~m}^{2}$ and there are 10 electric vehicles in the company fleet (the fleet C).

\section{B. Optimal Transformer sizing}

According to the steps detailed in III-A, we compute the rated active power, $P_{\text {rated }}=252 \mathrm{~kW}$, in the case without PV panels nor EV.

Considering this rated power, we compare the overloading periods with the requirements from [12]. Results are provided in Fig. 3. The sizing method is efficient, and no overloading period excesses the recommended limits.

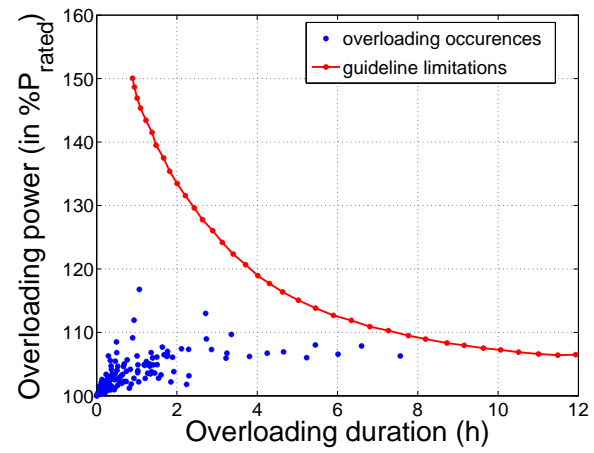

Fig. 3. Operating conditions of the transformer (no EV \& no PV)

\section{Transformer operating conditions with the introduction of $P V$ and $E V s$}

Then, according to the methodology explained previously, we successively add the PV panels and the EVs in the ecodistrict, first without any smart charging strategy, then with the EMS described in section III-C.

Fig. 4 shows the monotonically decreasing maximal daily substation power (in absolute value) without EV and with EV (with and without EMS). It is noticeable that the EMS allows a $25 \%$ reduction of the substation peak power in comparison with the unmanaged charging scenario.

Finally, we compare the transformer overloading occurrences under the two scenarios (with and without EMS). Results are provided in Fig. 5. 
TABLE III

RESULTS: SCENARIO COMPARISON

\begin{tabular}{lllll}
\hline Items & $\begin{array}{l}\mathrm{P}_{\text {max_global }} \\
(\mathrm{kW})\end{array}$ & $\begin{array}{l}\mathrm{E}_{\text {ex }} \\
(\mathrm{MWh})\end{array}$ & $\begin{array}{l}\text { Duration } \\
(\mathrm{h})\end{array}$ & $\begin{array}{l}\mathrm{P}_{\text {sub_ave }} \\
(\mathrm{kW})\end{array}$ \\
\hline Non EMS & 488 & 21.2 & 613 & 35 \\
EMS & 376 & 2.0 & 186 & 11 \\
$\begin{array}{l}\text { Improvement } \\
\text { ratio (\%) }\end{array}$ & 23 & 90 & 70 & 71 \\
\hline
\end{tabular}

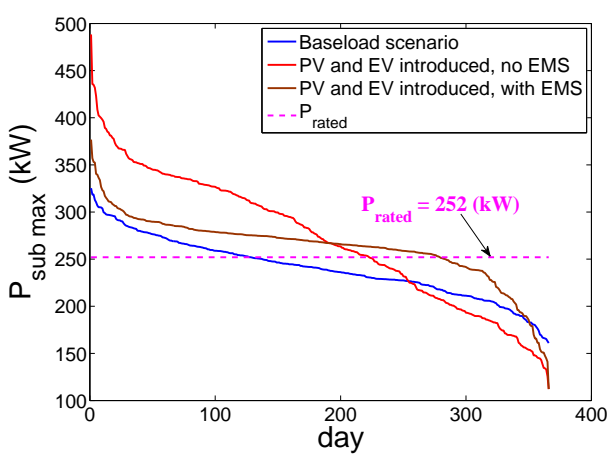

Fig. 4. Daily maximal substation power during the whole year with the different scenarios

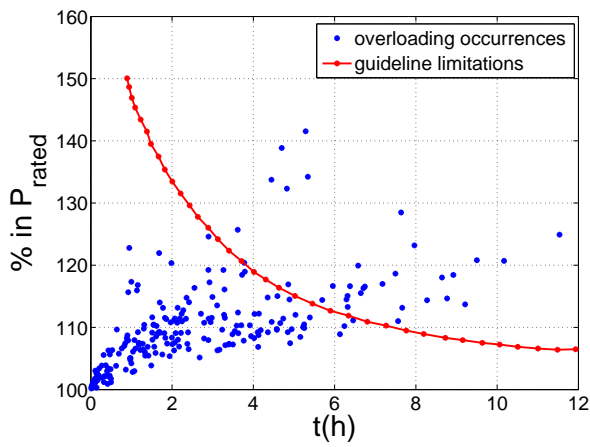

(a) Without EMS

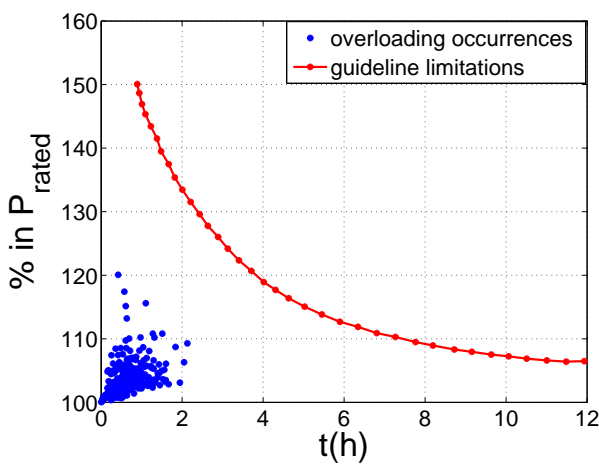

(b) With EMS

Fig. 5. Operating conditions of the transformer during overloading occurrences, with respect to the limitations provided in [12]

Because of the introduction of PV panels and unmanaged
EVs in the eco-district, there are more than 30 occurrences where transformer overloading capability is exceeded (Fig. 5a). Conversely, with the implementation of the EMS, all overloading periods are within the acceptable limits(Fig. 5b). The results are corroborated with those provided in table III, which compares the two strategies in terms of absolute maximal daily substation power ( $\mathrm{P}_{\text {max_global }}$ ), exceeded exchanged energy $\left(\mathrm{E}_{e x},(6)\right)$, cumulative overloading durations and average substation power $\left(\mathrm{P}_{\text {sub_ave }}\right)$ during the overloading periods.

\section{CONClusion}

In this paper, the rated power of a distribution transformer is computed to be compliant with the thermal limits. Then the operating conditions with the introduction of renewable sources and electric vehicles are also studied.

The flexibility provided by the EVs is used to reduce the risks of large overloading in the transformer. The proposed EMS allows to increase the margin regarding the thermal limits. This margin can be used to accept more EVs without risks of critical overloading or to postpone transformer reinforcement. An additional study will allow to define the optimal relationship between the PV surface and the number of $\mathrm{EV}$ to reach the transformer thermal limits.

\section{REFERENCES}

[1] S. Sharma, "System inertial frequency response estimation and impact of renewable resources in ERCOT Interconnection," Power and Energy Society, pp. 1-6, Jul. 2011.

[2] S. Eftekharnejad, V. Vittal, B. Keel, and J. Loehr, "Impact of increased penetration of photovoltaic generation on power systems," IEEE Transactions on Power Systems, vol. 28, no. 2, pp. 893-901, May 2013.

[3] J. O'Sullivan, A. Rogers, D. Flynn, P. Smith, A. Mullane, and M. O'Malley, "Studying the Maximum Instantaneous Non-Synchronous Generation in an Island SystemFrequency Stability Challenges in Ireland," IEEE Transactions on Power Systems, vol. 29, no. 6, pp. $2943-$ 2951, Nov. 2014

[4] Z. Darabi and M. Ferdowsi, "Aggregated Impact of Plug-in Hybrid Electric Vehicles on Electricity Demand Profile," IEEE Transactions on Sustainable Energy, vol. 2, no. 4, pp. 501-508, Oct. 2011.

[5] R. C. Green, L. Wang, and M. Alam, "The impact of plug-in hybrid electric vehicles on distribution networks: A review and outlook," Renewable and Sustainable Energy Reviews, vol. 15, no. 1, pp. 544553, Jan. 2011.

[6] K. Clement-Nyns, E. Haesen, and J. Driesen, "The impact of vehicle-togrid on the distribution grid," Electric Power Systems Research, vol. 81, no. 1, pp. 185-192, Jan. 2011.

[7] L. Igualada, C. Corchero, M. Cruz-Zambrano, and F.-J. Heredia, "Optimal Energy Management for a Residential Microgrid Including a Vehicle-to-Grid System," IEEE Transactions on Smart Grid, vol. 5, no. 4, pp. 2163-2172, Jul. 2014. [Online]. Available: http: //ieeexplore.ieee.org/lpdocs/epic03/wrapper.htm?arnumber $=6839093$

[8] I. Richardson, M. Thomson, D. Infield, and C. Clifford, "Domestic electricity use: A high-resolution energy demand model," Energy and Buildings, vol. 42, no. 10, pp. 1878-1887, Oct. 2010.

[9] CGDD, "Livre Vert sur les infrastructures de recharge ouvertes au public pour les vehicules decarbones," pp. 1-198, 2013.

[10] Cross-border Mobility for EVs, "Online publications," 2013. [Online]. Available: http://crome.forschung.kit.edu/francais/57.php

[11] Commissariat General au Developpement Durable, "Les vehicules electriques en perspectives," 2011.

[12] Schneider Electric, "Guide de la distribution electrique basse tension et HTA," p. B100, 2009. 